\title{
CONTRASTIVE RESEARCH IN BULGARIAN AND SLAVIC Phraseology
}

\author{
LILIA KRUMOVA-TSVETKOVA \\ INSTITUTE FOR BULGARIAN LANGUAGE, BULGARIAN ACADEMY OF SCIENCES \\ lilia.krumova@abv.bg
}

Recent years have seen a growing interest in the research in phraseology both in Bulgarian and in European linguistics. This trend may be interpreted as a reaction to the globalisation processes that are going on in a number of languages as phraseology represents the part of the lexical wealth in which national specificity is most visible. It is this part of the lexis that reflects national memory, the peculiarities of the national perception of the world and the historical and cultural features encoded in the language.

This issue of the Journal is dedicated to the contrastive study of phraseology in Slavic languages. The articles included in it propose a contrastive perspective to the phraseological wealth of close and unrelated languages, revealing both common characteristics and tendencies, as well as national peculiarities and specificities.

Part of the studies deal with comparisons between the Bulgarian and the Russian phraseological system. The lexical similarity of the two closely related languages, due both to linguistic and to cultural contacts, has attracted researchers' interest.

Diana Blagoeva's paper titled Neophrazeologization in Bulgarian (in Comparison with Russian) tackles a characteristic process in contemporary language development. The author studies phraseological units from the end of the $20^{\text {th }}$ and the beginning of the $21^{\text {st }}$ century and proposes an analysis of the most active mechanisms and structural-semantic patterns on which new phraseological units are modelled. She goes on to discuss the sources for enrichment of the phraseological stock of the two languages and current processes such as the expansion of new colloquial phraseology and the penetration of phraseological units from different sociolects and certain substandard strata into the common language.

In her article A Comparison of the Phraseological Stock of Bulgarian and Russian (Development and Problems) Stefka Georgieva tracks the stages of phraseological nomination in the two languages. The author draws conclusions 
about the considerable extent of similarity in the phraseological stocks of Bulgarian and Russian and the changes in borrowing patterns imposed by extralinguistic factors.

A study of stable comparisons in Russian and Bulgarian is presented in Teodora Krasteva's article The Notion of Drunkenness in Stable Comparisons in the Bulgarian and the Russian Language. The author establishes relations of equivalence between set expressions with the semantics of drunkenness in the two languages on the basis of data from the Bulgarian National Corpus and the Russian National Corpus.

Ivo Panchev's article Proverbs Related to Money in three Slavic Linguocultures: Bulgarian, Russian, and Slovak provides an analysis of interesting linguistic material: proverbs and sayings containing lexemes denoting money in three Slavic cultures. The author explores scenarios and culturemes based on these proverbs and analyses the differences in the comparisons and metaphors found in the three languages.

The paper titled Conceptualization of Intelligence and Stupidity in Bulgarian and Romanian Phraseology by the Romanian researcher Cristina-Andreea Radu-Bejenaru presents a comparison between two neighbouring, but unrelated languages. The study is based on the theory of conceptual metaphors and delves into such important features of phraseological units as motivation and compositionality. Based on an analysis of Bulgarian and Romanian phraseological units denoting intelligence and stupidity, the author outlines well-defined similarities between the two languages.

The contribution of the Polish researchers Iliana Genew-Puhalewa, Milena Hebal-Jezierska, Joanna Bilińska is a broad-based multilingual study. The article, titled Slavic Phraseology for Expressing Visual Semantics, explores material from Bulgarian, Polish, Slovenian and Czech in a contrastive perspective. The analysis progresses from meaning to form and draws conclusions about the remarkable formal similarity found across the four Slavic languages.

The Polish researcher Maciej Jaskot focuses his attention on the reflection of cultural components in phraseological units. His paper by the same name, Reflecting Cultural Components in Phraseological Units, is a linguocultural study drawing on material from Polish, Bulgarian, Ukrainian, Russian, Spanish and Italian. The author proves that the phraseological meaning is a complex semantic and conceptual whole in which cultural information is encoded and preserved. Particular attention is paid to phraseoculturemes which bear a relation to cultural codes.

Palmira Legurska and Teodora Krasteva's article Cataloguing of Stable Comparisons in the Bulgarian Language Based on the Bulgarian National Corpus deals with an intriguing project for compiling a catalogue of stable and nonstable comparisons in Bulgarian. The authors present the organisation of the catalogue according to sections, the comparison words for which an explication is proposed and the features on which the comparison is formed. They go on to 
outline the possibilities for employing the catalogue for linguistic and linguocultural purposes and for its integration in contrastive studies.

Boris Parashkevov offers interesting reflections on the origin and structure of the word светотатство ('blasphemy').

Issue 2/2019 of Balgarski ezik provides an opportunity for everyone interested in contrastive phraseology to get acquainted with the latest research in this linguistic field.

$\square$ Prof. Lilia Krumova-Tsvetkova, DSc Department of Bulgarian Lexicology and Lexicography Institute for Bulgarian Language, Bulgarian Academy of Sciences 52 Shipchenski prohod, Bl. 17, Sofia 1113, Bulgaria

Published: 28 June 2019 